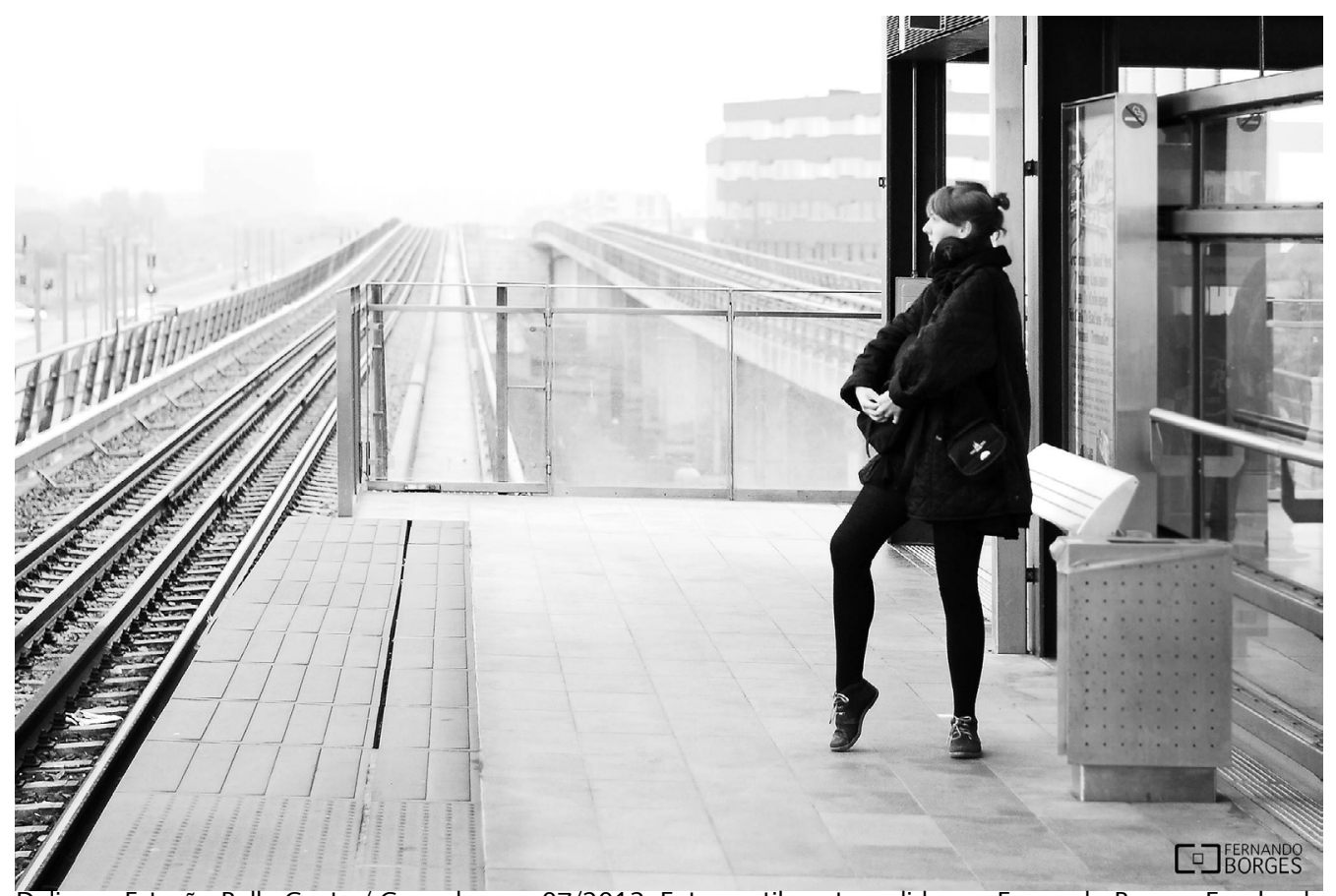

Delicacy. Estação Bella Center/ Copenhagen. 07/2013. Foto gentilmente cedida por Fernando Borges. Facebook: Fernando Borges Photography https://www.facebook.com/pages/FernandoBorgesPhotography/2113020656968 $98 ? \mathrm{ref}=\mathrm{hl}$ 


\title{
Identidade, auto-imagem e felicidade no mundo virtual
}

\author{
Maria Raquel da Cruz Duran ${ }^{1}$ \\ Maria Renata da Cruz Duran²
}

\section{Resumo:}

Pretendemos compreender a importância da Internet como veículo de discussão de valores sociais e sua relação com o capital social, por meio de estudo netnográfico das relações sociais entre indivíduos na formulação da identidade presente em Weblogs, onde as dinâmicas de sociabilidade entre público e privado são significados e preservados conforme antigas obsessões, tais como a da felicidade.

Palavras-chave: Ciberespaço. Weblogs. Identidade. Auto-imagem. Netnografia.

\section{ABSTRACT:}

We intend to understand the importance of the Internet as a vehicle for discussion of social values and their relationship to social capital through a netnographic study of social relations between individuals in the (re) formulation of this identity Weblogs, where the dynamics of sociability between public and private meanings are re-prints and preserved as old obsessions, such as happiness.

Keynote: Cyberspace. Weblog. Identity. Self-image. Netnography.

\footnotetext{
1 Bacharel em Ciências Sociais pela UNESP/Araraquara, mestre em Ciência, Tecnologia e Sociedade pela Universidade Federal de São Carlos (UFSCAR) e doutoranda em Antropologia Social na Universidade de São Paulo (USP). Leciona a disciplina de antropologia na Universidade Estadual do Mato Grosso do Sul (UEMS). Seu e-mail é clavedera@yahoo.com.br.

2 Doutora, mestre e graduada em História pela UNESP/Franca e leciona História Moderna e Contemporânea na Universidade Estadual de Londrina (UEL). Seu e-mail de contato é mariarenataduran@gmail.com . 
Quando navegamos pela rede mundial de computadores sempre nos deparamos com páginas em que transbordam sentimentos íntimos acerca das dificuldades vivenciadas pelas pessoas em seus relacionamentos com o mundo, com outras pessoas, consigo mesmas. Como um diário on-line, os Weblogs ${ }^{3}$, apelidados de Blogs, representam algumas destas páginas pessoais na Internet. Nelas o ciberespaço é utilizado como mecanismo de interação entre indivíduos, que publicam histórias, ideias ou imagens, muito populares, haja vista a facilidade de seu manejo tecnológico, que dispensa conhecimentos aprofundados, por exemplo, de $\mathrm{HTML}$, como podemos observar abaixo:

A prática de escrita dos blogs, entretanto, coloca em evidência as mais diversas questões humanas para que elas sejam lidas e discutidas pelo Outro. Não importa que outras pessoas reconheçam a depressão ou a falta de perspectiva na carreira profissional; o importante é que as histórias circulem e ocupem o espaço da rede. (KOMESU, 2004, p.115).

Como páginas pessoais, os blogs trazem também características de seu autor (o bloggeiro), na tentativa de personalização de tal website. Observa-se que no processo de 'montagem' do próprio blog está a presença de elementos identitários que seriam uma forma de figuração de quem é o bloggeiro ou de como ele gostaria de ser visto, à procura de um reconhecimento de si no outro e vice versa.

\begin{abstract}
Entende-se que o blog representaria, na sua forma e conteúdo, os contornos de uma nascente sociedade pós-moderna, que privilegia a ética da estética, ou seja, de ser apenas em relação ao outro, de reconhecer-se no outro a partir do compartilhamento de sentimentos, idéias e atitudes. Sendo assim, o blog, na sua essência (diário virtual) teria tamanha repercussão na contemporaneidade em função de ser produto e (re) produtor de uma parcela de indivíduos que encontra na rede a possibilidade de se comunicar com o outro, de tocar o outro através de uma narrativa bem particular que pode variar desde a confecção de artigos, crônicas, até a exposição de fatos e histórias de interesses peculiares como poesia, fotografias e relatos autobiográficos. (ROCHA, 2003, p. 74)
\end{abstract}

Partícipes da "cultura Internet" (RECUERO, 2004), os blogs buscam uma apropriação individual do ciberespaço, que é, simultaneamente, coletiva. Essa apropriação, bem como a "cultura internet" acessada aqui por meio dos blogs compõe um novo tipo de mídia na sociedade contemporânea, tornando-se assim, um campo no qual a identidade dos indivíduos se apresenta, sendo uma fonte de conhecimento dos fatores que a compõem: seus valores, sentimentos, desejos e paixões, tanto para as ciências sociais quanto para outras áreas afins - como, por exemplo, a psicologia.

Destarte, neste trabalho interdisciplinar, tentou-se esboçar uma história da auto-imagem nos blogs contemporâneos, a partir de uma netnografia dos "blogueiros" em sua busca pela definição de uma ideia de felicidade.

\title{
1. A busca pela imagem íntima do mundo
}

O ambiente de proximidade entre o aspecto individual e o coletivo, proporcionado

3 Segundo Blood (2000), Weblogs vem da junção de web (rede) com logs (registros). Os Weblogs ou registros de (ou na) rede foram criados pelo editor do site robot wisdom weblog, John Barger, em dezembro de 1997. 
pelo chamado ciberespaço ${ }^{4}$, produz novos sentidos, novas identidades e novas imagens no mecanismo de comunicação cultural gerado pela atualidade. Estas inovaçõessensoriais e práticas são redefinidas dentro de categorias sociais, tais como coletivo e individual, desterritorializando-as e modificando-as. (RECUERO, 2004, p. 21).

Este espaço virtual, que desterritorializa as relações sociais, habita uma transnacionalidade, onde a 'abolição do espaço' é possível, podendo deslocar as pessoas para quaisquer pontos, lugares e caminhos, o que substituiria a experiência sensorial por uma comunicação abstrata, uma digitalização das experiências humanas "[...] onde o outro não é mais que informação, identidade sem corpo nem rosto". (LIPOVETSKY, 2007, p. 281-2). Ou seja, a imagem produzida em meio digital é virtual (diz respeito à imaginação), mas não visual (relativa ao "objeto-imagem"): eis a imagem de que tratamos nesse texto.

$\mathrm{Na}$ comunidade virtual, a interação, - laço e o capital social coabitam num espaço virtual, sendo que este espaço mostra-se, a princípio, mais democrático do que outros, pois seu acesso depende de uma constituição de individualidade autorepresentada, referenciada ou construída. Assim, "a apropriação das ferramentas de Comunicação Mediada por Computador (CMC) é constantemente perpassada pela construção de si, tornando o ciberespaço reconhecível como um espaço individual" (RECUERO, 2008, p. 70).

Para Tarcyanie Santos (2005), o ciberespaço nos dá acesso à fabricação de um 4 "Por ciberespaço entendemos a extensão virtual da realidade, onde os produtos imateriais e simbólicos da experiência humana passam a se converter em pixels (contração de picture element) na tela do computador, com este passando a ser uma espécie de extensão da experiência humana". (MACHADO, 2002, p.2) mundo por meio de um duplo movimento: o de distinção do espaço físico - sendo que no espaço virtual poderíamos nos privar das possíveis dificuldades emocionais constituintes do espaço material, do 'caos' exterior e interior - e o de sua reafirmação, pois cria coletivamente novas experiências que repercutem no mundo real. (SANTOS, 2005, p. 8). Não obstante, para Silva, "A sociedade eletrônica simula a via do real e caracteriza-se pela inexistência do face a face, permitindo mais fôlego para que a sociedade possa investir na sua individualidade" (SILVA, M \& SILVA, C, 2006, p. 5).

Este mundo virtual composto por um espaço de difusão novo e pelo compartilhamento de valores, experiências e visões de mundo apresentados com imensa intimidade a um leitor, na maioria das vezes desconhecido, significa a auto-expressão daqueles que individualmente não poderiam se expressar de outro modo que não em rede (MACHADO, 2002). Nessa onda de autoexpressão e de construção e exposição de uma (nova) identidade, os blogs ou 'ciberdiários', passam a ser espaços privilegiados para compreensão e descrição contemporânea da autoimagem dos indivíduos e, no limite, de sua identidade.

As novas tecnologias (a propósito da nossa
visão maquínica nos estudos sobre as formas
simbólicas), antes de instaurar uma crise de
representação, refletem o momento em que há
o crescimento de complexidade na cognição,
nas linguagens, na produção e organização
do conhecimento. (MONTEIRO: 2006, p. 32)

A transformação promovida pelo ciberespaço colabora para a ideia de que é possível dispor do poder de controle sobre si próprio (corpo/imagem), prazer este que muitos chamam de felicidade. 
Esta é uma presumível explicação para o crescimento potencial que tem demonstrado a comunidade bloggeira no mundo. Assim sendo, os blogs contribuem para a afirmação da individualidade e de uma nova maneira de construir/inventar a auto-representação social.

E não é só isso. [...] deparamo-nos com uma espécie de método de auto-sugestão espontânea destinado a fazer frente aos efeitos deprimentes de um julgamento-balanço negativo sobre si próprio. [...] Na sociedade de hiperconsumo, os indivíduos não se protegem mais contra o mau-olhado alheio, mas contra seus próprios julgamentos negativos que, muito desvantajosos, lhes devolvem uma imagem penosa de si próprios. Tratase, no essencial, de uma atitude que visa a conjurar o desencorajamento, a manter a confiança em si mesmo. (LIPOVETSKY, 2007, p.320)

À medida que atentamos para os discursos nos Weblogs - caracteristicamente fundamentados sob discursos de afirmação/ negação do espaço físico -, percebemos a reprodução da "unidade dos contrários" inserida na ideia de identidade: por um lado uma perspectiva que afirma o ideal (busca da utopia e negação da realidade); e por outro, um prisma que afiança o real (favorecendo as ideias ascéticas, em prol da reunião de mais bens materiais ou imateriais, reproduzindo os mecanismos atuais de controle social como uma espécie de 'melhoramento' da realidade). Esse paradoxo é incomum em discursos propositados, de modo que, nos blogs, a liberdade de que seu autor dispõe, promove a apresentação de posturas contrárias acerca da identidade. Segundo Monteiro,

O devir do virtual é de natureza paradoxal, de acordo com Deleuze (1998) em seu paradoxo de sentido (contra o bom senso e o senso comum, os elementos da doxa) em que a simultaneidade torna impossível uma identificação, colocando a ênfase ora em um, ora em outro aspecto, não sendo possível, portanto, calcar-se na determinação da significação ou da identidade fixa dos referentes ontológicos (das classificações biblioteconômicas), porque o paradoxo do sentido está em repartir-se em espaço aberto, em vez do espaço fechado das propriedades e das classes, em que o bom senso reúne todos os sentidos. [...] A importância do paradoxo do sentido reside no fato de que, no ciberespaço, destrói o bom senso como sentido único, uma vez que é a indicação dos dois sentidos ao mesmo tempo, e destrói o senso comum como designação de identidades fixas. (MONTEIRO, 2006, p. 33 - grifos da autora)

Destarte, a partir do momento em que a tecnologia torna-se capaz de articular a vida cotidiana das pessoas, ela passa a integrar as relações entre elas, e começa a participar também da formação da percepção humana sobre o mundo, seus laços sociais, sua cultura. Cria-se, a partir dessa imagem, uma ação, "configurando" elementos virtuais e visuais em prol de uma existência compartilhada. Como nos explica Mário Albornoz:

El desarrollo tecnológico, tal como ocurrió antes com El telefono o El automóvil y ahora com Internet, contituye "sistemas tecnológicos" en los logros de la ciencia. Como consecuencia de este proceso numerosos científicos sociales comenzaron a interesarse por las relaciones entre a la ciencia, la tecnologia y la sociedad (lo que hoy se conoce como el campo de los estudios CTS). (ALBORNOZ, 2007, p. 60)

A utilização do espaço virtual como forma de interação é figurativa das transformações modernas. A rede social - muitas vezes formada pela exposição da identidade, pela busca de associação com a comunidade virtual ou na junção delas, ou seja, uma forma híbrida de relacionamento com o ciberespaço 
- nos auxilia a pensar a apropriação deste espaço como elemento constituinte de uma redescoberta da cultura, num mundo que se recria através da ciência e da tecnologia, indicando elementos da qualidade das conexões estabelecidas entre os atores para compreensão do conteúdo destes laços sociais que se formam (RECUERO, 2009, p.122).

Nesse quadro geral, a intimidade virtual do mundo contemporâneo é, diria William Gibson, autor da famosa triologia "Neuromancer", profundamente individualizada, autocentrada, ou programada, a partir de maneiras de lidar muito singularizadas e fragmentárias de estruturas arquetípicas previamente estabelecidas com a finalidade de possibilitar condições de expansão a essa individualidade, bem como a manutenção de uma distância "de segurança" em relação ao outro. Restritos aos próprios "compartimentos", cada byte, cada indivíduo tem, virtualmente, espaço suficiente para "ser" quem é, ou melhor, para criar a "imagem" desse ser.

\section{O desenho de uma imagem social no mundo}

"A modernidade é uma cultura de risco", assinalou Anthony Giddens (2002), destacando, ainda, que, na modernidade, "a influência de acontecimentos distantes sobre eventos próximos, e sobre as intimidades do eu, se torna cada vez mais comum" (2002, p. 11-12). Tal como as transformações na autoidentidade, diretamente ligadas às conexões sociais de grande amplitude, em que "o nível do distanciamento tempo-espaço introduzido pela alta modernidade é tão amplo que, pela primeira vez na história humana, "eu" e "sociedade" estão inter-relacionados num meio global" (idem, 2002, p. 36), por outras palavras, o indivíduo em rede se dilui na própria rede social, daí a importância de sua imagem "virtual".

No livro A identidade cultural na pósmodernidade de Stuart Hall, trabalha com a mesma hipótese, a internalização do exterior e a externalização do interior do sujeito fariam deste um ser que nasce e morre rapidamente, tal como uma imagem -dado que ele se confunde com ela própria. Instantâneas, as imagens individuais concebem, por similaridade/homogeneidade, uma paisagem virtual à que damos o nome de rede, eis o porquê a rede se confunde com o indivíduo: o pano de fundo sobre o qual nos vemos é comum, exaltando a identidade de nossos tipos sociais.

O intercâmbio entre imaginário, virtual e real e não mais o distanciamento entre eles constituem os novos espaços da subjetividade moderna. Nessa contemporaneidade, o 'infotrabalhador' ou o trabalhador cognitivo ${ }^{5}$ deve voltar-se para uma reprodução dualista do sistema social. A super-racionalização do mundo humano e a consequente desmistificação do mesmo, o homem que controla e constrói seu futuro, sua produção, sua sabedoria, incutidas como uma nova forma do viver social/individual acarretou a concepção do homem moderno e do homem contemporâneo.

Um termo muito usado atualmente para caracterizar esta contemporaneidade é designado 'pós-modernismo'. Frederic

\footnotetext{
5 "O infotrabalhador talvez possa ser descrito como um artesão, porque muitas vezes tem o poder de organizar seu tempo suas relações. Seu desejo segue diretrizes de forte desterritorialização, de forte densidade. [...] $\mathrm{O}$ investimento de desejo, que para o artesão fortemente ligado às necessidades da comunidade territorial tinha um caráter tranqüilizante, para o infotrabalhador segue linhas ansiógenas, não tranquilizantes, linhas continuamente redefinidas. [...] O trabalho cognitivo é essencialmente trabalho da comunicação, ou comunicação empenhada em trabalhar". (BERARDI, 2005, p. 49)
} 
Jameson o caracteriza como uma estrutura totalizante para a cultura, nele

[...] cada consciência é um mundo fechado, de tal forma que a representação da totalidade social tem agora que assumir a forma (impossível) de uma coexistência desses mundos subjetivos selados, que é na verdade um passar de navios no meio da noite, um movimento centrífugo de linhas e de planos que não podem nunca se intersectar. (JAMESON, 1991, p. 407).

O pós-modernismo seria, portanto, um dos protagonistas na reprodução do capitalismo multinacional atual, expandindo a cultura ao domínio social, de onde tudo é cultura. No modernismo existem a natureza e a eventualidade de uma mudança da cultura sobre ela. No pós-modernismo o processo de modernização está completo, a cultura tomou o lugar da natureza: ela mesma é uma segunda natureza, é um produto dentro da esfera da mercadoria. O pós-modernismo não é reflexo do novo sistema capitalista descentralizado, mas sim uma modificação sistêmica do próprio capitalismo: "[...] O pós-modernismo é o consumo da própria produção de mercadorias como processo" (1991, p.14).

Para Jameson, são características do pósmodernismo: a abolição da fronteiras entre a alta cultura/cultura de massa e vida cotidiana/ arte, a promiscuidade de estilos, o ecletismo, a celebração da "ausência de profundidade" da cultura. Dele emergem quatro modos de análise da cultura mais recorrentes, dialética (essência/aparência), freudiana (latente/ manifesto), existencialista (autenticidade/ inautenticidade) e semiótica (significado/ significante). Em todas, segundo Jamenson, a auto-imagem é cifrada de acordo com rótulos auto impostos: o que a pessoa fala de si é o que ela é, afinal de contas, nesse mercado, todos tentam comprovar seu valor, daí a configuração de janelas de informação que comportam fragmentos sociais mas, dificilmente, hiperlinks combinados, como Ted Nelson propunha em seu projeto Xanadú ${ }^{\text {. }}$

Em O Capital, a principal obra de Karl Marx, as mercadorias são diferenciadas de acordo com seus valores de troca. Subsome daí a percepção do valor de uso do trabalho, transformando este trabalho concreto e qualitativo em algo abstrato e quantitativo (MARX - In: FORACCHI \& MARTINS, 1977, p.49). Braverman, por sua vez, demostrou que a tecnologia e a ciência foram/são utilizadas como instrumento principal para uma maior acumulação de capital e, portanto, transformação do processo do trabalho, no período do final do século XIX até 1970.

Os efeitos que o desenvolvimento das tecnologias cientificas e da produtividade lançaram no movimento trabalhista, após os grandes conflitos mundiais, são muitos. $\mathrm{O}$ principal deles é a mudança na atitude deste movimento, que passa de reivindicador de um novo modo de produção à negociador de um maior espaço de decisão dentro do mesmo modo de produção. Para Jameson, o conhecimento tecnológico-científico e da produção material e imaterial como a matéria do capital, ou seja: a troca da máquina pela informação, a mutação da consciência em prática inconsciente de (re) produção de bens (i) materiais, como motor de movimentação do sistema.

Negociantes de si próprios, os indivíduos desenham sua imagem no mundo virtual tendo em vista uma estética da recepção. Constroem, para tal, uma teoria do efeito, baseada no modo como sua auto-imagem postada em rede gera maior ou menor prestígio em torno de si, maiores ou menores vantagens sociais (Jauss, 2002). Resta saber, conforme indica Norbert

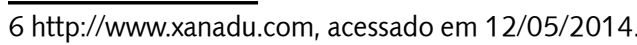


Elias em A sociedade dos indivíduos por quais critérios e medidas de valor esse processo de individualização se efetiva, ou quiçá, apenas se aventure.

\section{A busca inatingível do mundo ideal no mundo virtual}

Um dos temas mais recorrentes no universo virtual circunscrito aos weblogs é a busca da felicidade. Entendida como um estádio superior de frequência existencial, a felicidade é buscada desde os primórdios da sociedade ocidental. Todavia, em nosso esquadro, o universo virtual contemporâneo, a felicidade tem seu berço no romantismo oitocentista, em obras como as de Goethe, mitos como o de Tristão e Isolda, imagens como as de Jean François Fragonard.

Já faz tempo, portanto, que essa felicidade é buscada de maneira desconfortável: inatingível e dependente do sacrifício, a busca pela felicidade, no mundo virtual, também se faz pela construção de uma auto-imagem de felicidade, se não de uma fusão entre a imagem de felicidade e a nossa própria imagem. As esperanças, entretanto, são redobradas: utópico por natureza, o universo virtual é um mundo criado pelo homem, que pode romper com o mundo existente, real, natural em que atuamos como seres restringidos pela natureza, pelo outro. Se ele [o mundo virtual] parte do ideal, pode ser utópico. Garantindo para si maior trânsito entre os afetos da utopia, o universo virtual é propenso às promessas, ilusões e expectativas de felicidade e, de maneira correlata, ao seu desencantamento.

De fato, se a consideramos comparativamente, a ideia de "mudar o mundo" tem um ar tão absurdo que acabamos por compreender que ela só possa ter surgido numa civilização que mantivera, durante largo tempo e implacavelmente, uma distinção absoluta entre a vida prometida ao homem e aquela que é, de fato, a dele. Essa loucura moderna enraíza-se no que foi chamado de absurdo da cruz. Recordo-me de Alexandre Koyré opondo, numa conversa, a loucura do Cristo ao bom senso do Buda. Eles têm, contudo, algo em comum: a preocupação exclusiva do indivíduo unida a - ou, melhor, fundada em uma desvalorização do mundo. (DUMONT, 1985, p. 43).

No mesmo ambiente em que se originaram as ideias de busca e de impossibilidade de conquista da felicidade nos deparamos com a condição de que se faz necessário um pagamento mediante o esforço ou sacrifício próprio, para a 'realização' daquele desejo/ vontade, reduzindo toda a idéia da "eterna busca da felicidade terrena, inatingível" em um poderoso discurso de preço, compondo finalmente, toda a semântica que envolve tal ideologia. Marshall Sahlins comenta tal redução das propriedades sociais em valores de mercado, ou seja, ter que "pagar" pelo que fez ou quer com as seguintes palavras:

A ideia geral é que o sistema mundial é a
expressão racional de lógicas culturais relativas,
isto é, nos termos de valor de troca. (...) Assim
como Galileu pensava que os números eram
a linguagem do mundo físico, a burguesia
deleitou-se em acreditar que o universo
cultural é redutível a um discurso de preço-a
despeito de outros povos resistirem a uma
e outra ideia, povoando sua existência com
outras considerações. (SAHLINS, 2004b, p.
157)

O resultado de tal desobediência é a cisão entre humanidade e mundo, é a invenção de que a verdade do mundo disfarçou-se e que, portanto, vivenciamos o mito da caverna; nunca atingiremos a felicidade plena, pois esta é espiritual. Obedecendo nossos desejos 
desobedecemos a Deus, tornamo-nos escravos de nossas necessidades, a punição é a eterna busca desta felicidade que se perdeu no inalcançável mundo das essências (SAHLINS, 2004c, p. 567).

A sociedade limita o prazer individual, pois quando o indivíduo se torna coletivo deve respeitar as vontades alheias em prol da boa convivência. A oposição sociedade/ indivíduo contribui para a infelicidade terrena e para a visão utópica, transcendental, espiritual, de realização da felicidade. Todavia, sendo a felicidade algo superior, transcendental, elevado, ideal, perfeito; e o mundo imperfeição, purgatório, inferior, materialidade, apenas a morte libertaria o espírito do corpo, somente com a morte seriamos felizes plenamente. $\mathrm{O}$ mundo e a realidade são vistos como algo ruim onde tudo nos causa desprazer, porque nos separa do eu.

Passamos a interpretar as coisas limitadamente, como se o que doesse fosse ruim e o que desse prazer fosse bom, a necessidade torna-se desejo e o desejo tornase necessidade. O homem transforma-se em escravo de seus apetites, eterno sonhador em busca da felicidade, neste contexto é que se aplica a dialética da civilização. A felicidade e a realidade são opostas, a sociedade parece oprimir a realização de nossas vontades, a virtualidade não.

Marcuse em "Eros e Civilização" defende que a dialética da civilização oprime a busca pela felicidade uma vez que esta é vista como o império da vontade e do prazer, cuja falta de saciedade geraria um movimento de violência constante e impeditivo do equilíbrio social. Para ele,

Quando Schopenhauer define a essência do ser como vontade, expõe uma carência e agressão insaciáveis que devem ser redimidas a todo custo. Para Schopenhauer, só são redimíveis em sua negação absoluta, a própria vontade deve ficar em repouso - para um fim. Mas o ideal de Nirvana contém a afirmação: o fim é a realização, a gratificação. Nirvana é a imagem do princípio do prazer. Como tal emerge, ainda numa forma repressiva, nos dramas de Richard Wagner: repressiva porque (como em qualquer boa teologia e moralidade) a realização exige aqui o sacrifício da felicidade terrena. (MARCUSE, 1968, p. 113).

$\mathrm{Na}$ rede, um dos efeitos mais nocivos dessa carência insaciável é a superexposição, bem como a suspensão de regras sociais de apresentação de si. Se no âmbito público e material poucas pessoas andam desnudas, na rede a exposição do corpo é garantia de atenção, saciedade da carência de ser visto, reconhecido, desejado. Todavia, o conceito de felicidade aqui é tratado como compartilhado e reproduzido numa racionalidade de contrários. Racionalidade esta que se constrói no século XVIII, baseada na sensibilidade ao prazer e à dor ${ }^{7}$. A unidade de contrários observada na felicidade, também se reproduz na forma discursiva atual e pode ser notada numa busca incessante e quase sempre frustrada da felicidade nos mais variados weblogs, o que, portanto, suspende a virtualidade como território livre das barreiras do real.

Os blogs consultados para este artigo abordam esta ideia dualista de luta e sofrimento mundanos como esforços exigidos à obtenção do prazer querido e da elevação individual do espírito. O primeiro trecho citado é do blog "A vida leva o amor fica", o seguinte foi retirado do blog "O amor vence tudo. $\mathrm{O}$ amor que Deus escreve ninguém apaga".

Felicidade é confiança: fé e crença, trabalho e ação.

7 Principalmente á dor, que, segundo Sahlins (2004b, p. 487) é mais duradoura que o prazer e condição de sua possibilidade. 
Não se pode ter pressa de ser feliz, porque a felicidade vem devagarinho, como quem não quer nada.

Ser feliz não depende de dinheiro, não depende de saúde, nem de poder.

Felicidade não é fruto da ostentação, nem do luxo.

Felicidade é desprendimento, não é ambição. Só é feliz quem sabe suportar, perder, sofrer e perdoar.

Só é feliz quem sabe, sobretudo, amar ${ }^{8}$.

A felicidade não depende do que acontece ao nosso redor! Mas do que acontece dentro de nós! A felicidade se mede pela forma que enfrentamos as curvas da vida! É fácil sentir-se deprimido!

Portanto, a felicidade exige valentia! A felicidade não consiste em fazer sempre o que desejamos, mas sim, em querer bem o que fazemos! ${ }^{9}$

Neste tipo de mídia, muitos indivíduos expõem suas ânsias pela experimentação de um amor romântico, como elo perdido entre suas vidas e a felicidade almejada. Procuram seus pares, como supostas almas gêmeas que se perderam ao encarnarem no mundo material, encontram uma realidade oposta, que traz valores individualistas, amores descartáveis, metas/desejos renováveis, tais como pudemos notar nos trechos supracitados. De algum lugar do Brasil, o jovem Fabio Centenaro reitera essa tese ao postar a seguinte mensagem no dia 12 de julho de 2007, em seu blog:

Na minha opinião, todos temos o direito de sermos felizes, de estar com uma pessoa que gostamos e que nos traz a alegria de viver. Se um amor chegou ao fim, cabe aos dois seguirem suas vidas, cada um para o seu lado,

8 Retirado do site: http://its-gone.blogspot. com/2007/06/felicidade.html, sob o título 'Felicidade', postado às 11:30 horas na quinta feira, dia 7 de junho de 2007.

9 Retirado do site: http://cleomessias.blogspot. com/2007/07/felicidade_11.html, sob o título ; Felicidade', postado às 16:40 horas na quarta feira, dia 11 de julho de 2007. e começarem a jornada em busca da felicidade. Nunca é tarde para encontrar o amor. (...) Fomos feitos para amar e ser feliz e para isso que devemos viver, buscando o melhor para a nossa vida, sempre. Lembrando que sempre é hora de ser feliz, nunca, mas nunca é tarde demais. Temos sempre um novo dia pela frente, e devemos vivê-lo da melhor maneira possível. Uma frase que eu gosto muito de dizer é "It is never too late" (nunca é tarde demais) ${ }^{10}$.

A responsabilidade de encontrar o amor é de cada indivíduo, por isso a busca deve ser prática constante do eu, à medida que dela depende $\mathrm{a}$ conquista da felicidade. Neste caminho, muitos deverão ser os obstáculos, pois o mundo das regras, do homem, da matéria é oposto ao mundo espiritual. Neste ensejo, a busca da felicidade e do amor, como sua prerrogativa, são dois pontos essenciais na vida de Fabio Centenaro. Do mesmo modo, para Cleo Messias:

A felicidade é apenas uma parte integrante do amor. Isto é o que deve ser aprendido. $\mathrm{O}$ sofrimento também pertence ao amor. Este é o grande mistério do amor. A sua própria beleza e o seu próprio fardo. Em todo o esforço que se realiza para o aprendizado do amor é preciso considerar sempre a doação e o sacrifício ao lado da satisfação e da alegria. A pessoa terá sempre que abdicar alguma coisa para possuir ou ganhar uma outra coisa. Terá que desembolsar algo para obter um bem maior e melhor para sua felicidade. É como plantar uma árvore frente a uma janela. Ganha sombra, mas perde uma parte da paisagem. Troca o silêncio pelo gorjeio da passarada ao amanhecer. É preciso considerar tudo isto quando nos dispomos a enfrentar o aprendizado do amor ${ }^{11}$

10 Retirado do site: http://www.centenaro.org/fabio/ quando-o-amor-acaba, sob o título "Quando o amor acaba", postado por Fabio Centenaro, acessado em 12 Julho de 2007 às 8 horas.

11 Retirado do site: http://cleomessias.blogspot. com/2007/07/aprendizado-do-amor.html, sob o título "Aprendizado do amor", postado às 08:59 horas da segunda-feira e acessado no dia 23 de julho de 2007. 
Para o bloggeiro, ao amor é imprescindível certa instrução, conquistada por meio de experiências dolorosas na maior parte das vezes. Paralelamente, a concepção espiritual/ onírica relacionada à felicidade, ou seja, sua configuração como algo superior, elevado, de difícil acesso; bem como, a idéia de que é preciso persegui-la em meio aos percalços que o seu oponente mundano/material cria, promovendo a sensação de dúvida perante a existência da felicidade terrena, estão postas nas palavras de Antônio Stélio:

Claro que existe. O difícil é conquistá-la nesta vida efêmera e cheia de frescuras. Nós, seres humanos, não raro, sempre queremos mais e mais e, esse não contentamento, é que torna a felicidade, para muitos, uma quimera. (...) Da mesma forma há homens e mulheres que chegam a rezar para que Deus, em sua infinita bondade, coloque em seus caminhos o príncipe ou a princesa encantada, enfim, o grande amor que une homem e mulher numa paixão ardente e eterna, onde ambos possam nadar no lago do amor em todos os ocasos. Mas, tanto homem quanto mulher, quando conquistam esse amor através de um parceiro ou parceira, de forma quase amiúde, acabam por destruí-lo com coisas mesquinhas, como o ciúme e a recusa de ceder para manter acesa a chama dessa união. Resultado: não tem reza que dê jeito e ambos, após separaremse, choram lágrimas de infelicidade e auto compaixão. Daí voltam a indagar: a felicidade existe de verdade? (...) A felicidade, saibam todos, não é algo material: é um estado de espírito que tem como andor uma vida simples e sincera. A felicidade não se adorna com ouro, mas com amor e ternura. Amor e ternura, inclusive, por nós mesmos ${ }^{12}$.

Constata-se o mesmo tipo de eloquência no tratamento do tema 'felicidade' na argumentação de muitos dos diários virtuais que acessamos, à medida que percebemos nestes blogs a atualização mitológica da dialética:

12 Retirado do site:http://antoniostelio.blogspot. com/2007/06/felicidade-existe.html, sob o título "A felicidade Existe?", postado por Antônio Stélio às 17:20.
Oi! Meu nome é Felicidade.

Faço parte da vida daqueles que tem amigos,

Pois ter amigos é ser Feliz.

Faço parte da vida daqueles que acreditam na força do Amor, que acreditam que para uma história bonita não há ponto final.

Eu sou casada sabiam?

Sou casada com o Tempo.

(...)

Juntos, eu e o Tempo tivemos três filhos:

A Amizade, a Sabedoria, e o Amor.

(...)

O caçula é o Amor.

Ah! Como esse me dá trabalho!

É teimoso, às vezes só quer morar em um lugar...

Eu vivo dizendo:

Amor, você foi feito para morar em dois corações,

não em apenas um.

O Amor é complexo, mas é lindo, muito lindo!

Quando ele começa a fazer estragos

eu chamo logo o pai dele,

o Tempo, e aí o Tempo sai fechando todas as feridas que o Amor abriu!

Uma pessoa muito importante me ensinou uma coisa:

Tudo no final sempre dá certo, se ainda, não deu, é porque não chegou o final.

Por isso, acredite sempre na minha família.

Acredite no Tempo, na Amizade, na

Sabedoria e,

principalmente no Amor.

Aí, com certeza um dia, eu, a Felicidade, baterei à sua porta!

Tenha Tempo para os Sonhos

Eles conduzem sua carruagem para as Estrelas $^{13}$.

Ao atentar para a felicidade enquanto (a) ideologia de reprodução da dialética da civilização moderna, ou seja, o agir com desprendimento, porém (b) buscando o eterno, fator preponderante na essência da felicidade vigente nos mitos e, portanto, a

13 Retirado do site: http://jocendir.spaces.live.com/ Blog/cns!9E3E34387C20247!1309.entry, sob o título "Felicidade" de autor desconhecido, postado às 10:56 horas do dia 11 de junho de 2007. 
idealização de sua perpetuação e completude, conjuntamente à sua (c) não realização em vida, almejamos destacar as contradições do universo virtual no que diz respeito aos superpoderes de um eu "auto-imaginado". Ao evocar a felicidade, notamos o quanto nossas velhas amarras ainda nos mantém pregados num gramado verde (nossa natureza), mesmo quando lutamos para alcançar alguma felicidade, mesmo que melancólica, tal como registra Lars Von Trier em uma de suas mais fortes imagens do filme Melancolia (2011). Neste satélite "azul" que se choca com o nosso, a felicidade é a melancolia, o tédio, o sacrifício, a falta de ação, a incapacidade de vislumbrar como ocorrerá a catástrofe: o limite da imaginação.

Analisar, por meio da Netnografia, as relações entre sociedade e mito da felicidade foi um de nossos objetivos, destacar a importância (e a permanência) do mito como linguagem de interpretação da cultura moderna, dadas suas contradições (ou vistas as contradições inerentes à essa) e da utilização da Internet como fundamentadora de redes sociais onde laços e capitais sociais são constantemente renovados, reformados, reinventados, revolucionados nos faz lembrar que o pensamento pode servir como mediação para a formação de um sistema, sociedade, e não apenas a ação - parafraseando Da Matta. (1987, p. 42).

Discutir a felicidade significa refletir sobre o que é importante na vida. Significa ponderar os méritos relativos de diferentes caminhos e pôr em relevo a extensão do hiato que nos separa, individual e coletivamente, da melhor vida ao nosso alcance. (...) A vida que se vive é um desentendimento fluido, uma média alegre entre a grandeza que não há e a felicidade que não pode haver (GIANNETTI, 2002, p. 183)

\section{Considerações finais}

Sendo a felicidade um porvir e o virtual um universo criado a partir de uma expectativa de futuro, nos pareceu interessante a comparação de ambos para a definição de algumas das chaves analíticas dos valores que compõem a sociedade contemporânea, seja ela presencial ou virtual. Como vimos, o virtual, ainda que composto por algumas especificidades, tende a reproduzir/ manter/ amalgamar a sociedade presencial tradicional. Diferente de uma mônada ou uma bolha, como geralmente é tratado, o virtual é parte do real (e, para brincar com Hegel, o real também é virtual) e nele, a felicidade é comparável a uma fotografia cuja imagem, indefinidamente reproduzível, permanece retratando velhas soluções (tais como a do amor romântico), todavia, de maneira cada vez mais fragmentada (individual) e comercial (mercadorias fetichizadas). É interessante notar, ainda, o quanto um padrão estético antecede um padrão ético, numa sociedade que tem como carro-chefe de sua produção, cada vez mais, o mundo virtual. Resta saber, se mesmo atrasada, a ética chegará para figurar nesse retrato de família.

\section{Referências Bibliográficas}

ALBORNOZ, Mario. Los problemas de La ciência yel poder. Centro de Estudios sobre Ciencia, Desarrollo y Educación Superior - REDES, Argentina. Revista CTS, n 8, vol.3 Abril de 2007 (pág. 47-65).

AMARAL, A; NATAL, G; \& VIANA, L. Netnografia como aporte metodológico da pesquisa em comunicação digital. In: FAMECOS/ PUCRS, Comunicação Cibernética. $N^{\circ} 20$. Porto Alegre: 12/2008.

BERMAN, Marshall. Tudo que é sólido desmancha 
no ar: a aventura da modernidade. São Paulo: Companhia das Letras, 2007. Tradução de Carlos Felipe Moisés, Ana Maria L. Ioriatti.

BLOOD, R. Weblogs: a history and perspective. Disponível em: http://www.rebeccablood. net/essays/weblogs_history.html. Acesso em 20/01/08.

DEMO, P. Dialética da Felicidade: um olhar sociológico pós-moderno. Petrópoles: Vozes, 2001. v.1.

DHAVAN V, Shah; KWAK, Nojin; HOLBERT, R. Lance. "Connecting" and "Disconnecting" with Civic Life: patterns of Internet Use and the production of Social Capital. Open University Library: 2007. Taylor \& Francis. DOI: 10.1080/105846001750322952. (<http:// dx.doi.org/10.1080/105846001750322952)

GIANNETTI, E. Felicidade: diálogos sobre o bemestar na civilização. São Paulo: Companhia das Letras, 2002.

GIDDENS, A. Modernidade e identidade. Rio de Janeiro, Jorge Zahar Editores, 2002.

GODELIER, Maurice. A parte ideal do real. In: Ensaio sobre a ideologia humana, 1978.

HALL, Stuart. A identidade cultural na pósmodernidade. Rio de Janeiro: DP\&A, 2001. Tradução de Tomaz Tadeu da Silva, Guacira Lopes Louro - $4^{\circ}$ edição.

HARVEY, David. A Condição Pós-Moderna. São Paulo: Edições Loyola, 1992.

JAMESON, F. Pós-Modernismo. São Paulo: Editora Ática, 2000.

JAUSS, Hans Robert. A Estética da Recepção: Colocac口ões Gerais. In: LIMA, Luiz Costa (Coord. e Trad.). A literatura e o leitor: Textos de estética da recepção. 2. ed. rev. e ampl. Rio de Janeiro: Paz e Terra, 2002a. p. 67-84.

KOMESU, F. Blogs e as práticas de escrita sobre si na internet. In: Hipertexto e gêneros digitais: novas formas de construção do sentido. (Organizado por Luiz Antônio Marcuschi e Antônio Carlos Xavier). Rio de Janeiro: Lucerna, 2004. p. 110-119. Acessado em 11/06/2008.

LESSIG, L. Cultura Livre. (Tradução de Fábio Emilio Costa). Versão digital disponível em: < http://www.rau-tu.unicamp.br/nou-rau/ softwarelivre/document/?view $=144>$. Acesso em: 6/04/2008.
LIPOVETSKY, G. A felicidade paradoxal: ensaio sobre a sociedade de hiperconsumo. (Tradução de Maria Lúcia Machado). São Paulo: Companhia das Letras, 2007.

MARCUSE, H. Eros e civilização: uma interpretação filosófica do pensamento de Freud. Rio de Janeiro: Zahar Editores, 1968.

MONTEIRO, S. O ciberespaço e os mecanismos de busca: novas máquinas semióticas. Brasília: Ci. Inf; vol. 35, n.1, p. 31-38, jan./abr.2006. Acessado em 11/06/2008.

RECUERO, R. da C. Diga-me com quem falas e dir-te-ei quem és: a conversação mediada pelo computador e as redes sociais na internet. Revista FAMECOS. Porto Alegre, $n^{\circ} 38$, abril de 2009, quadrimestral.

RECUERO, R. da C. Webrings: as redes de sociabilidade e os Weblogs. Porto Alegre: Revista FAMECOS/ PUCRS: sessões do imaginário, cinema, cibercultura, tecnologias da imagem, n.11, 2004. Acessado em 11/06/2008.

ROCHA, P. J. Blogs: sentimentos em rede compartilhados na pós-modernidade. Porto Alegre: Revista FAMECOS/ PUCRS: mídia, cultura e tecnologia, vol.I, n.22, 2005. Acessado em $11 / 06 / 2008$.

SAHLINS, M. Cultura na Prática. Rio de Janeiro: Editora UFRJ, 2004b.

SANTOS, T. C. O Ciberespaço: Dimensão antropológica das sociedades de controle. Revista TEXTOS de la CiberSociedad: 2005, vol. 6 . Temática variada - ISSN 1577-3760. Disponível em: http://www.cibersociedad.net. Acessado em 28/05/2008. São Paulo: Record - $1^{\circ}$ ed., 2001.

SILVA, C. A. F. da; SILVA, M. T. C. da. A dimensão Sociespacial do Ciberespaço: uma nota. Rio de Janeiro: Projeto Tamandaré (UFF - Universidade Federal Fluminense), 2006. Disponível em: http:// www.tamandare.g12.br/indexciber.htm. Acessado em 28/05/2008. 
